\title{
Serodeconversion of HIV Antibody-Positive AIDS Patients Following Treatment with V-1 Immunitor
}

\author{
Orapun Metadilogkul, ${ }^{1}$ Vichai Jirathitikal, ${ }^{2}$ and Aldar S. Bourinbaiar ${ }^{2}$ \\ ${ }^{1}$ Occupational and Environmental Medicine Association of Thailand, Rajavithi General Hospital, \\ Ministry of Public Health, Rajavithi Road, Bangkok 10400, Thailand \\ ${ }^{2}$ Immunitor USA Inc., 9308 48th Avenue, College Park, MD 20740, USA
}

Correspondence should be addressed to Aldar S. Bourinbaiar, info@immunitor.com

Received 30 May 2008; Revised 7 August 2008; Accepted 7 September 2008

Recommended by Ali Ouaissi

It is extremely rare when HIV seropositive adult patients experience spontaneous loss of antibodies, that is, seroreversion. The disappearance of HIV antibodies was occasionally attributed to iatrogenic intervention-serodeconversion. Such interventions include: HAART; oral interferon; Chinese herbal remedies; and therapeutic AIDS vaccines derived from pooled blood. Oral therapeutic, alloimmune AIDS vaccine, V-1 Immunitor (V1), was administered to 60000 HIV-positive Thai patients. The administration of V1 resulted in serodeconversion among 23 individuals. The patient group consisted of 9 females (39\%) and 14 males (61\%) including two 2-year-old boys. The age range was 2-58 years with mean/median 29/29.3 years. Patients were tested seropositive for HIV at least once before being enrolled on V1. The duration of treatment until discovery of seronegative status ranged between 2 weeks and 15 months with average/median 7.2/8 months. Time to seronegativity was correlated with baseline disease stage $(R=0.62 ; P=.002)$. The seronegative status was positively associated with $\mathrm{V} 1$-induced undetectable or low viral load $(R=0.65 ; P=.0008)$. The odds ratio analysis comparing the outcome of our study with published surveys of diagnostic accuracy of laboratory tests suggested that the probability of HIV antibody testing error was remote $(P<.000001)$. The possible causes responsible for this unusual phenomenon are discussed.

Copyright () 2009 Orapun Metadilogkul et al. This is an open access article distributed under the Creative Commons Attribution License, which permits unrestricted use, distribution, and reproduction in any medium, provided the original work is properly cited.

\section{Introduction}

The HIV seropositivity revealed by an antibody test is indicative of virus infection. Due to a small proportion of false-positive, false-negative, and ambiguous (indeterminate) findings occurring in a general population, this test is not perfect but remains, however, the first-line laboratory procedure for diagnostic purposes. It is currently accepted that antibody tests are nearly 100\% sensitive and about $99 \%$ specific $[1,2]$. The frequency of false-positive HIV serology in a low-prevalence population, for example, military recruits from rural United States, is 1/135000 [1], while for blood donors in Minnesota is 6/million [2]. A survey of 5 million blood donors' samples found that the prevalence of false positives was $1 / 251000$ [1]. To reduce the chances of technical or clerical error, the antibody tests are confirmed by additional tests like ELISA, western blot, and PCR analysis. When tests are combined, for example, ELISA and western blot, the false-positive rate has been reported to be as low as 1/100000 [3]. Others have indicated that even when tests are combined, about $3 \%$ of the investigated sera were false-positive, false-negative, or noninterpretable [4].

It is extremely unusual when symptomatic or asymptomatic individuals with culture- or PCR-confirmed HIV infection do not produce virus-directed antibodies and remain persistently negative beyond the expected window period. A few such cases have been reported in the literature, and most of which were due to agammaglobulinemia of unknown immune dysfunction [5-11]. These exceptions only reinforce the general notion that once a person is diagnosed with HIV, he or she remains antibody-positive for the rest of his or her life.

Newborn babies usually lose HIV antibodies acquired from their HIV-positive mothers. The average time to seroreversion after birth is usually $12-16$-maximum 18 months [12]. However, with the exception of very few instances, 
these infants are not HIV-infected [13]. An adult with confirmed HIV infection seldom changes seropositive status. Occasionally, this has been observed among individuals who were at the terminal stage of disease [14, 15]. Cases of spontaneous seroreversion among patients from other categories are exceedingly rare [16-18].

In addition to cases of spontaneous loss of antibodies, there are several reports attributing this phenomenon to iatrogenic intervention, referred to as serodeconversion. The earliest known report is related to administration of lowdose oral interferon, whereby 18 out of 204 treated patients became HIV-negative [19]. A clinical study of Chinese herbal preparations revealed serodeconversion in eight AIDS patients [20]. Two recent reports have shown for the first time that patients with acute or early HIV infection may lose HIV antibodies as a result of highly active antiretroviral therapy $[21,22]$, supporting the notion that serodeconversion seldom occurs in patients on antiviral therapy [1]. Finally, both therapeutic AIDS vaccines produced from the blood of HIV patients, that is, Nigerian Abalaka's vaccine and Cameroonian Anomah Ngu's vaccine, were reported to produce serodeconversion in several dozen AIDS patients $[23,24]$.

V-1 Immunitor (V1) - the first commercial therapeutic AIDS vaccine-has been registered by the Thai FDA as a food supplement and experimental drug [25]. The vaccine comprises heat-inactivated HIV antigens derived from pooled blood of HIV-infected donors. Extensive preclinical studies have shown that V1 is safe [25]. In a longitudinal survey in 400 patients, about $85 \%$ reported improvement, $6 \%$ reported no difference, and $9 \%$ reported minor adverse reactions, which did not last more than one week [26]. Our earlier open-label and subsequent placebo-controlled clinical studies have shown that $\mathrm{V} 1$ administration increases absolute CD4 and CD8 cell counts in both HIV-positive and HIV-negative subjects [27-29]. Viral load measurements have shown statistically significant trend toward decrease [27]. Other clinical benefits included the reversal of AIDSassociated wasting and normalization of elevated liver enzymes in HIV-positive patients coinfected with hepatitis viruses [26]. Patients on V1 rarely develop new fungal or bacterial infections, suggesting that V1 restores the mucosal immune response to opportunistic infections [26]. Finally, in a survival study, the end-stage AIDS patients had 15.8 times longer life expectancy than those who declined V1 treatment [30]. This single clinical endpoint is clearly more important than surrogate endpoints such as viral load and T-cell counts. In this study, we analyze yet another phenomenon associated with V1 therapy, that is, an observation that some AIDS patients who received V1 became HIV-antibody-negative.

\section{Materials and Methods}

2.1. Patients. Sixty thousand patients from Thailand with documented history of HIV infection have received or are currently receiving $\mathrm{V} 1$. In this retrospective survey, every patient who became aware of HIV-antibody-negative status following treatment with V1 was considered for the analysis. Patients who did not have reliable antibody test, traceable to

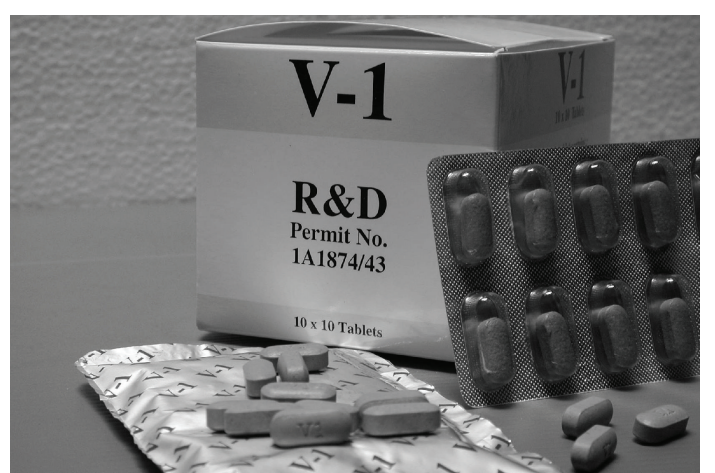

FIGURE 1: The appearance of V-1 Immunitor (V1) therapeutic oral AIDS vaccine.

the original issuing lab, were not included and only those with confirmed serodeconversion as compared to baseline status were included in this survey. The physical examination and patients' interviews were performed at Rajavithi General Hospital in Bangkok. Patients self-administered either one or two V1 tablets per day. The dose for children was twice smaller. With the exception of one patient (no. 22), none of them received conventional antiretroviral therapy or participated in any AIDS vaccine trials conducted in Thailand during treatment period. Patient no. 22, a twoyear-old boy from Tanzania, was on AZT monotherapy for a few months shortly after the birth but due to drug intolerance and lack of clinical improvement he discontinued treatment before starting on V1.

2.2. Vaccine. V-1 Immunitor (V1) is derived from specially processed heat and chemically inactivated, pooled blood of HIV-infected Thai donors. The vaccine is formulated into an oral tablet according to a proprietary process developed by us [25]. As pooled blood from unrelated donors was used for vaccine manufacturing, V1 can be regarded as an allovaccine since in addition to viral proteins it also contains alloantigens from the blood. The vaccine is manufactured in Thailand by Immunitor (Thailand) Co., Ltd., and is approved by Thai Food and Drug Administration (FDA) as a dietary supplement and investigational drug. V-1 Immunitor is provided as $850 \mathrm{mg}$ coated tablet - ten of which are sealed in a "blister" package (Figure 1).

2.3. HIV Tests. Most of patients' sera were examined by rapid tests for HIV antibodies (Bioline HIV1/2, Immunochemical Lab, Thailand and Determine HIV1/2 Abbott/Dainabot, Japan). Another approved antibody test used in Thailand as a second-line test is ELISA or enzyme immunoassay (EIA). These tests are also commercially available: UniForm II Ag/Ab kit (Organon Technika, The Netherlands) or HIV1/2 (Abbott Laboratories, USA). Occasionally, latex particle agglutination test (GPA, Serodia-HIV 1/2, Fujirebio Inc., Japan) was utilized as an alternative to ELISA. The choice of second-line tests depended on their availability at the testing lab and patients' ability to pay for them. In some cases, commercial western blot assay was conducted in addition to antibody tests (HIV Blot 2.2, Genelabs 
Diagnostics, Singapore). As tests were performed in different labs, the QA/QC standards may vary but these variables were beyond our control due to retrospective nature of this study.

2.4. Viral Load Measurement. Plasma viral concentrations were measured at various independent hospitals and commercial labs at patients' own choice. As PCR tests are expensive, very few patients were able to afford such tests. Depending on the individual lab, the commercial viral load kits were used without any specific preference. These quantitative PCR kits were either RNA PCR kit (Roche Diagnostic Systems, Inc., Branchburg, NJ, USA) or branched DNA kit (Bayer, Tarrytown, NJ, USA). The sensitivities of these tests were 400 and 50 viral copies per $\mathrm{mL}$, respectively. In addition, qualitative tests for HIV-1 were performed by in-house developed PCR method according to our own published protocol [31]. The lowest detection threshold of this test was estimated to be not less than $100 \mathrm{HIV}$ copies per mL.

2.5. Statistical Analysis. Data were analyzed with StatMost software version 2.5 (DataMost Corporation, Salt Lake City, Utah, USA) and SISA - free online program - with courtesy of Daan Uitenbroek. The main parametric pairwise test was Student's $t$-test. The odds ratio (OR) was estimated at 95\% Wald confidence interval (CI). For assessment of correlation between seronegative status and viral load, we have used nonparametric Spearman's rank-order test. The significance level for all tests was set at $P \leq .05$.

\section{Results}

The patient group consisted of 9 females (39\%) and 14 males (61\%) including 2 two-year-old boys. Ages ranged within 258 years with a mean age of 29 years (median age $=29.5$ years). The duration of V1 treatment until a patient sought to check the antibody status ranged between 2 weeks and 15 months with an average of 7.2 months (median range = 8 months). All patients were tested for HIV seropositivity prior to administration of V1. While most of them were tested only once before treatment initiation, on average, there were two positive tests per patient. Once patients knew the seronegative status, many of them had tests repeated, often at different labs to ascertain that they were truly negative. Thus, the average number of post-treatment tests was slightly higher (3 tests) but not statistically significant. The results are summarized in Table 1 which shows only those tests for which we have traceable records.

At baseline, we had 13 (56.5\%) patients who qualified as having full-blown AIDS, while the remaining $2(8.7 \%)$ and $8(34.8 \%)$ patients had the WHO stage 2 and 3 symptoms, respectively. Since patients with fewer symptoms were recovering faster, the correlation analysis was conducted to see if there is a relation between severity of disease and time to serodeconversion. The results indicate that earlier you start treatment, faster you expect to see the disappearance of HIV antibodies (Spearman's rank correlation, $R=0.620793 ; P=$ .0015773).

In nine patients, viral loads were barely detectable or undetectable after treatment, but unfortunately four of these patients had no matching PCR tests at study entry. Qualitative PCR tests which were conducted at the end of study were either positive or negative. But the majority of patients had not tested for viral load primarily due to the fact that they could not afford expensive PCR tests. Nevertheless, from what is available to us, there is a clear impression that serodeconversion correlates with lowered or undetectable viral load.

Unfortunately, we do not have the complete pairwise set of data to confirm this impression by a robust parametric test. We thus have performed nonparametric Spearman's rank order correlation analysis on available outcome results, that is, nine patients: nos. $1,2,3,6,8,9,10,11$, and 23 . We assume that four patients-nos. 3, 6, 8, and 23-had positive PCR results prior to the therapy. Each viral load test, whether positive or negative, was entered as a binary value. For example, patient no. 1 had three negative results and a total of 3 were entered into negative results' column; patient no. 3 had 2 negatives and 1 positive reading, which were entered into negative and positive results' columns, respectively. Patients who had no results had zeros entered as values. In this manner, we have constructed a two-way table to evaluate whether HIV-seronegative status had any association with negative or positive PCR results. The results revealed positive linear relationship with $R=0.64842$ at $P=$ .000819. We thus conclude that serodeconversion correlates positively with low or undetectable viral load.

Another reliable test that could be performed on available data is establishment of the odds ratio, which could tell whether our findings differ from published incidence of false-positive or false-negative results in large populations of individuals screened for HIV antibodies. Such a statistical test was aimed to reveal whether the observed incidence of serodeconversion, that is, 23 individuals out of 60000, could happen randomly as a result of laboratory error. This analysis was performed in $2 \times 2$ contingency table comparing side by side our data with published surveys of diagnostic accuracy of HIV tests. The results are presented in Table 2. As can be seen from Table 2, what we have observed is statistically different in every single case. All obtained OR values were distant from 1-a ratio that one would expect to see if there was no difference between our outcome and frequencies reported by others.

\section{Discussion}

Due to the retrospective nature of this study, the data, especially concerning viral load, are incomplete. Nevertheless, it is clear that obtained results are highly unusual. Why would previously HIV-antibody-positive patients become seronegative after treatment with V1?

The possibility that all these patients were false-positive at the baseline is unlikely since they were symptomatic and sought V1 treatment because they were suffering from AIDSrelated symptoms. These symptoms, that is, low CD4 counts; weight loss; a whole range of opportunistic infections: such as oral thrush, TB, skin lesions, persistent diarrhea, and in one case even Kaposi's sarcoma, were severe enough to score them as belonging to advanced disease stage [33]. 
TABLE 1: Summary of lab tests on serodeconverted HIV-positive patients treated with V1.

\begin{tabular}{|c|c|c|c|c|c|c|c|c|c|c|c|c|}
\hline No. & Gender & Age & $\begin{array}{l}\text { HIV } \\
\text { disease } \\
\text { stage as } \\
\text { per the } \\
\text { WHO } \\
\text { criteria }\end{array}$ & $\begin{array}{l}\text { Months } \\
\text { since known } \\
\text { as being } \\
\text { infected as } \\
\text { per patient's } \\
\text { recollection }\end{array}$ & $\begin{array}{l}\text { First } \\
\text { tested } \\
\text { positive } \\
(\mathrm{m} / \mathrm{y})\end{array}$ & $\begin{array}{l}\text { Months } \\
\text { on V1 }\end{array}$ & $\begin{array}{l}\text { HIV } \\
\text { positive } \\
\text { times }^{\mathrm{a}}\end{array}$ & $\begin{array}{l}\text { HIV } \\
\text { negative } \\
\text { times }^{b}\end{array}$ & $\begin{array}{l}\text { HIV PCR } \\
\text { copies } \\
\text { before }^{\mathrm{c}}\end{array}$ & $\begin{array}{l}\text { HIV PCR } \\
\text { copies } \\
\text { after }\end{array}$ & $\begin{array}{l}\text { Qualitative } \\
\text { PCR }^{\text {d }} \\
\text { positive }\end{array}$ & $\begin{array}{l}\text { Qualitative } \\
\text { PCR }^{\mathrm{d}} \\
\text { negative }\end{array}$ \\
\hline 01 & $\mathrm{~F}$ & 30 & 4 & 1 & $3 / 00$ & 14 & 2 & 5 & 617 & $<50$ & & 2 \\
\hline 02 & $\mathrm{~F}$ & 38 & 2 & 0.5 & $7 / 01$ & 2 & 2 & 4 & & $<50$ & & 1 \\
\hline 03 & $\mathrm{~F}$ & 31 & 3 & 18 & $9 / 01$ & 4 & 4 & 8 & & & 2 & 1 \\
\hline 04 & $\mathrm{~F}$ & 24 & 4 & 18 & $10 / 01$ & 4 & 1 & 1 & & & & \\
\hline 05 & $\mathrm{~F}$ & 27 & 3 & 2 & $9 / 01$ & 2 & 4 & 1 & 1830 & & & \\
\hline 06 & M & 26 & 3 & Unknown & $4 / 01$ & 1 & 2 & 2 & & $<50$ & & \\
\hline 07 & $\mathrm{~F}$ & 19 & 3 & Unknown & $6 / 01$ & 1 & 1 & 3 & & & & \\
\hline 08 & M & 28 & 4 & 15 & $6 / 02$ & 10 & 1 & 7 & & & & 1 \\
\hline 09 & M & 32 & 3 & 7 & $4 / 00$ & 15 & 1 & 10 & $127 ; 2710$ & $<400 ;<50$ & 1 & \\
\hline 10 & $\mathrm{~F}$ & 28 & 3 & 7 & $8 / 01$ & 3 & 5 & 0 & $1140 ; 1620$ & & 1 & 1 \\
\hline 11 & $\mathrm{~F}$ & 29 & 4 & 2 & $11 / 01$ & 8 & 7 & 0 & & $<50 ;<400$ & 2 & 2 \\
\hline 12 & M & 24 & 4 & 24 & $5 / 02$ & 11 & 3 & 5 & 43900 & & & \\
\hline 13 & M & 28 & 3 & 12 & $2 / 02$ & 9 & 1 & 4 & & & & \\
\hline 14 & M & 30 & 4 & 36 & $3 / 02$ & 10 & 1 & 3 & & & & \\
\hline 15 & M & 40 & 4 & 120 & $3 / 02$ & 10 & 1 & 1 & & & & \\
\hline 16 & M & 58 & 4 & 6 & $1 / 02$ & 6 & 1 & 1 & & & & \\
\hline 17 & M & 32 & 2 & 0.5 & $12 / 01$ & 0.5 & 1 & 1 & & & & \\
\hline 18 & M & 38 & 4 & 96 & $2 / 02$ & 11 & 1 & 3 & & & & \\
\hline 19 & M & 43 & 4 & 32 & $5 / 02$ & 11 & 1 & 4 & & & & \\
\hline 20 & M & 33 & 3 & Unknown & $5 / 02$ & 3 & 1 & 1 & & & & \\
\hline 21 & M & 2 & 4 & 24 & $8 / 02$ & 15 & 1 & 2 & & & & \\
\hline 22 & M & 2 & 4 & 24 & $3 / 02$ & 2 & 1 & 3 & & & & \\
\hline 23 & $\mathrm{~F}$ & 29 & 4 & Unknown & $2 / 02$ & 13 & 1 & 1 & & $<400$ & & \\
\hline
\end{tabular}

${ }^{a}$ Tests were done at baseline before treatment initiation.

b Tests were performed after treatment initiation.

${ }^{\mathrm{c}}$ Tests were done after treatment initiation, not at baseline.

${ }^{\mathrm{d}}$ Due to high cost, some patients had qualitative PCR tests, that is, positive or negative, rather than quantitative ones-all of such tests were carried out after treatment initiation.

TABLE 2: Odds ratio of observed serodeconversion rate, that is, 23 out of 60,000 patients, in comparison to published incidence rate of erroneous HIV tests.

\begin{tabular}{ccccc}
\hline Report & Observed & Total number & Odds ratio with CI at 95\% & Two-sided $P$ value \\
\hline$[1]$ & 1 & 135000 & OR $=0.0193 ;$ CI $=0.002-0.1432$ & $P<.0000000001$ \\
{$[1]$} & 1 & OR $=0.0104 ;$ CI $=0.001-0.077$ & $P<.0000000001$ \\
{$[2]$} & 151000 & OR $=0.0157 ; \mathrm{CI}=0.0064-0.038$ & $P<.0000000001$ \\
{$[3]$} & 1000000 & OR $=0.0261 ; \mathrm{CI}=0.004-0.1932$ & $P=.0000000024$ \\
{$[4]$} & 100000 & OR $=78.362 ; \mathrm{CI}=45.53-134.86$ & $P<.0000000001$ \\
{$[32]$} & 11 & 1032 & OR $=0.0324 ; \mathrm{CI}=0.0207-0.051$ & $P<.0000000001$ \\
\hline
\end{tabular}

One may argue that clinical symptoms were not HIVrelated and all these patients were initially false-positive due to random incidence of such cases in general population. This scenario, however, remains highly unlikely since, according to the "normal" incidence of false positives in healthy individuals, one would expect no more than $1 / 4$ $(0.25 \%)$ to $1 / 2(0.5 \%)$ false-positive persons among 60000 V1-treated individuals [1]. On the contrary, in placebo- controlled, randomized phase II clinical trial of V1 published in 2004, we have shown that one out of $29 \mathrm{~V} 1$-treated patients became HIV-negative, suggesting much higher conversion rate [29]. The cases of true, confirmed seroreversion, that is, a seroreactive or positive sample with subsequently one or more nonreactive samples from the same person, are extremely rare [10-18]. In fact, most, if not all, cases of apparent seroreversion seem to be errors of attribution or lab 
testing [1-4]. A survey on 2580974 army recruits identified 4911 seropositive individuals by two independent samples, among whom only six were potential seroreverters [32]. Further review of these cases revealed that five actually were HIV-seroreactive patients who had samples from nonreactive individuals mistakenly attributed to them, while the sixth had a testing error. Mistakes in the testing process were identified in other 26 cases indicating the cumulative error rate of 12.4 per 1 million individuals. In this paper, we included only those patients who had confirmed tests traceable to the original testing lab and excluded anyone who had indeterminate results or whose records could not be traced. The odds ratio analysis comparing our data with published reports of false-positive or false-negative cases in large surveys rules out that what we have observed is a random event due to testing error (see Table 2).

Even the two infants in our study who were born to HIVpositive mothers are unlikely to be false-positive since they were both symptomatic and tested repeatedly positive past the age of 18 months, a timepoint by which the newborns lose maternal antibodies [12, 13]. Table 1, however, shows only one positive baseline test for each of the boys since other tests could not be traced to original issuing labs.

Another aspect worthy of note is that patient no. 17 tested negative after 2 weeks on V1, whereas patients nos. 6 and 7 became seronegative after 1 month. As on average, it took 7-8 months and as long as 15 months to attain seronegative status; the two-week period appears to be very short. Nevertheless, considering that half life of anti-p24 IgG immunoglobulin is 11-19 days, it is possible that HIV antibodies were still present but their levels have decreased below detection limit of standard assays [34]. This possibility is not entirely implausible. The antibody tests of some of the patients were fluctuating from positive to negative and back to positive during the therapy suggesting that the levels of anti-HIV antibodies were at the borderline of detection threshold. Furthermore, despite being seronegative, four patients-nos. 3, 9, 10, and 11-were still showing the presence of the virus as detected by PCR analysis. Latter situation is reminiscent of extensively studied high-risk seronegative (HRSN) individuals who have remained HIVnegative despite repeated exposure to the virus. It has been shown recently that HRSNs often carry extraordinary low levels of HIV-1 DNA [35]. However, as opposed to our patients, these individuals are free of disease symptoms and are commonly known as long-term survivors.

It is not unusual to see the decline in antibodies in very late stage of HIV disease which may be explained, in part, by higher viral burden and reduced availability of circulating antibodies due to antibody-antigen complex formation. In our situation, as there is a documented decrease in viral burden, we would expect to see a surplus of antibodies rather than their reduction. Furthermore, time to reach seronegative status was not random. It was correlated with baseline disease stage, meaning that those who are better off initially were likely to require less time to convert than those with advanced disease $(R=0.62 ; P=.002)$. Incidentally, all three patients-nos. 17, 6, and 7-who converted to seronegative status under one-month time were all in earlier disease stage.
The therapeutic vaccination was first introduced into clinical practice by the French researcher Daniel Zagury as a treatment option for AIDS more than 20 years ago [36]. Due to inherent problems associated with HAART, this concept has become increasingly popular nowadays. However, nearly 30 therapeutic vaccine candidates were tested in over 60 clinical trials, but they have not produced any evidence of clinical benefit, let alone serodeconversion [37]. The only exception are pooled blood-derived AIDS vaccines, developed by Drs. Abalaka and Ngu, THIVAC and VANHIVAX, respectively, which produced favorable clinical outcomes and have caused serodeconversion in some of their patients $[23,24]$. Their results provide further support to a possibility that what we have observed with $\mathrm{V} 1$ is not due to testing or clerical error.

From the immunological point of view, this phenomenon seems to be related to an observation first made by Stott, who reported that macaques vaccinated with a preparation of whole killed human cells infected with SIV were fully protected against subsequent challenge [38]. Curiously, animals immunized with a control preparation consisting of killed human cells without SIV were also protected. This observation appears to relate to the fact that during the budding process through the cell membrane, SIV as well as HIV acquires several hundred host cell molecules [39]. Thus, the immunization with host's proteins was equal to or more effective than immunization with viral antigens. While the interpretation of Stott study has been contested, several studies appear to be in agreement with this seemingly unusual finding. For example, Lopalco et al. reported that the enigmatic phenomenon of exposure to HIV without seroconversion was associated with anticell auto-anti-bodies but not with HIV-neutralizing antibodies directed against viral antigens [40]. Sera from polytransfused, HIV-negative individuals who often develop immune responses against themselves, including anti-HLA antibodies, were shown to neutralize HIV-1 [41].

The concept that AIDS is an autoimmune disease and thus alloimmunization or in other words, immunization with autologous cellular antigens with or without HIV antigens, as a basis for immune-based therapy of HIV has been advocated at length by us and others [42, 43]. Several therapeutic approaches based on this concept have been proposed. Daniel Zagury, who pioneered therapeutic HIV immunization, made his original vaccine from formaldehyde-treated leukocytes derived from the blood of seropositive patients [36]. His vaccine has shown dramatic clinical improvements, but unfortunately his work has not been followed. The autologous T-cell vaccination developed by Abulafia-Lapid et al. has shown encouraging results with over 50\% (median of $70 \%$ ) increase in CD4 cell counts. Their vaccine consists of in vitro propagated, glutaraldehyde-inactivated, autologous T cells which are injected back to HIV-positive donors [44]. Remune is another vaccine in this category; however, due to the purification process of virus particles from the supernatant of cell culture, it may not possess sufficient quantity of alloantigens, which may explain persistent incertitude in clinical effect [45]. Oral feeding of alloantigens, as in case of $\mathrm{V} 1$, is an approach that makes sense since it induces immune 
tolerance-a strategy that has been shown effective in therapy of chronic hepatitis B and C-diseases that are caused by autoimmune reaction against virus-carrying liver cells rather than direct cytopathic effect of hepatitis viruses [4648]. Israeli et al. have shown that oral feeding of hepatitis B antigens in combination with allogeneic liver cells to patients with chronic hepatitis leads to a dose-dependent reduction of anti-HBV antibody titers - an observation that supports, albeit indirectly, our findings [46]. In fact, we have shown earlier that oral administration of $\mathrm{V} 1$ to normal healthy volunteers does not induce systemic anti-HIV antibodies [28].

These investigations relate to the often ignored notion of autoimmune nature of AIDS as a disease [42, 43]. If this concept is correct, then the prevailing AIDS vaccine strategy aimed at activating the immune response against HIV instead of inducing immune tolerance is flawed. Results of recent trial of therapeutic AIDS vaccine in which HIVdirected immune activation was associated with increase in viral load further support this notion [49]. The observed phenomenon of loss of antibodies against HIV and clinical improvement can be readily explained by tolerance induction. Due to paucity of guiding precedents relating to serodeconversion [50-52], the present findings need to be interpreted cautiously and additional case studies have to be acquired and analyzed to rule out any possible error.

\section{Acknowledgment}

This paper is dedicated to the memory of Ms. Sureeporn Limpasupalerk, the Senior Medical Technologist of Lerdsin Hospital who ended her life on October 17, 2002, after being unjustly accused by her superiors of making error in an HIV antibody test of a patient who became seronegative after treatment with V1. The authors did not know her personally and have learned about her fate from the media reports [53]. They express their admiration for her courage to stand behind her results, and convey their sincere condolences to her family and coworkers.

\section{References}

[1] J. G. Bartlett and J. E. Gallan, Medical Management of HIV, Chapter II, HIV Serology, Johns Hopkins University, Baltimore, Md, USA, 2003.

[2] K. L. MacDonald, J. B. Jackson, R. J. Bowman, et al., "Performance characteristics of serologic tests for human immunodeficiency virus type 1 (HIV-1) antibody among Minnesota blood donors. Public health and clinical implications," Annals of Internal Medicine, vol. 110, no. 8, pp. 617-621, 1989.

[3] R. M. Nakamura, D. J. Bylund, and K. E. Rooney, "Current status of clinical laboratory tests for the human immunodeficiency virus," Journal of Clinical Laboratory Analysis, vol. 4, no. 4, pp. 295-306, 1990.

[4] F. Gschnait, B. L. Schmidt, T. Schwarz, F. X. Heinz, and C. Kunz, "HIV (HTLV III/LAV) serology: experiences based on more than 42,000 tests," Wiener Klinische Wochenschrift, vol. 99, no. 15, pp. 536-539, 1987 (German).

[5] L. Montagnier, C. Brenner, S. Chamaret, et al., "Human immunodeficiency virus infection and AIDS in a person with negative serology," The Journal of Infectious Diseases, vol. 175, no. 4, pp. 955-959, 1997.
[6] J. M. Quiñonez, R. E. Begue, and R. W. Steele, "HIV seronegativity in an infant with the acquired immunodeficiency syndrome," Southern Medical Journal, vol. 91, no. 9, pp. 879-881, 1998.

[7] D. T. Imagawa, M. H. Lee, S. M. Wolinsky, et al., "Human immunodeficiency virus type 1 infection in homosexual men who remain seronegative for prolonged periods," The New England Journal of Medicine, vol. 320, no. 22, pp. 1458-1462, 1989.

[8] P. S. Sullivan, C. Schable, W. Koch, et al., "Persistently negative HIV-1 antibody enzyme immunoassay screening results for patients with HIV-1 infection and AIDS: serologic, clinical, and virologic results," AIDS, vol. 13, no. 1, pp. 89-96, 1999.

[9] L. Reimer, S. Mottice, C. Schable, et al., "Absence of detectable antibody in a patient infected with human immunodeficiency virus," Clinical Infectious Diseases, vol. 25, no. 1, pp. 98-100, 1997.

[10] D. L. Ellenberger, P. S. Sullivan, J. Dorn, et al., "Viral and immunologic examination of human immunodeficiency virus type 1-infected, persistently seronegative persons," The Journal of Infectious Diseases, vol. 180, no. 4, pp. 1033-1042, 1999.

[11] R. S. Root-Bernstein, "Five myths about AIDS that have misdirected research and treatment," Genetica, vol. 95, no. 1-3, pp. 111-132, 1995.

[12] C. J. Chantry, E. R. Cooper, S. I. Pelton, C. Zorilla, G. V. Hillyer, and C. Diaz, "Seroreversion in human immunodeficiency virus-exposed but uninfected infants," Pediatric Infectious Disease Journal, vol. 14, no. 5, pp. 382-387, 1995.

[13] S. S. Bakshi, S. Tetali, E. J. Abrams, M. O. Paul, and S. G. Pahwa, "Repeatedly positive human immunodeficiency virus type 1 DNA polymerase chain reaction in human immunodeficiency virus-exposed seroreverting infants," Pediatric Infectious Disease Journal, vol. 14, no. 8, pp. 658-662, 1995.

[14] M. Gutierrez, V. Soriano, R. Bravo, A. Vallejo, and J. GonzalezLahoz, "Seroreversion in patients with end-stage HIV infection," Vox Sanguinis, vol. 67, no. 2, pp. 238-239, 1994.

[15] H. L. Zaaijer, M. H. Bloemer, and P. N. Lelie, "Temporary seronegativity in a human immunodeficiency virus type 1-infected man," Journal of Medical Virology, vol. 51, no. 1, pp. 80-82, 1997.

[16] L. H. Perrin, R. Zubler, B. Hirschel, et al., "Reversal of positive serology for human immunodeficiency virus (HIV). Apropos of 2 case reports," Schweizerische Medizinische Wochenschrift, vol. 118, no. 45, pp. 1641-1644, 1988 (French).

[17] H. Farzadegan, M. A. Polis, S. M. Wolinsky, et al., "Loss of human immunodeficiency virus type 1 (HIV-1) antibodies with evidence of viral infection in asymptomatic homosexual men. A report from the Multicenter AIDS Cohort Study," Annals of Internal Medicine, vol. 108, no. 6, pp. 785-790, 1988.

[18] K. M. Coyne, J. V. Parry, M. Atkins, A. Pozniak, and A. McOwan, "Spontaneous HIV-1 seroreversion in an adult male," Sexually Transmitted Diseases, vol. 34, no. 9, pp. 627-630, 2007.

[19] D. K. Koech and A. O. Obel, "Efficacy of Kemron (low dose oral natural human interferon alpha) in the management of HIV-1 infection and acquired immune deficiency syndrome (AIDS)," East African Medical Journal, vol. 67, no. 7, supplement 2, pp. SS64-SS70, 1990.

[20] W. B. Lu, R. X. Wen, and C. F. Guan, "A report on 8 seronegative converted HIV/AIDS patients with traditional Chinese medicine," Zhongguo Zhong Xi Yi Jie He Za Zhi Zhongguo Zhongxiyi Jiehe Zazhi, vol. 17, no. 5, pp. 271-273, 1997 (Chinese). 
[21] S. Jurriaans, S. U. C. Sankatsing, J. M. Prins, et al., "HIV-1 seroreversion in an HIV-1-seropositive patient treated during acute infection with highly active antiretroviral therapy and mycophenoiate mofetil," AIDS, vol. 18, no. 11, pp. 1607-1608, 2004.

[22] S. Kassutto, M. N. Johnston, and E. S. Rosenberg, "Incomplete HIV type 1 antibody evolution and seroreversion in acutely infected individuals treated with early antiretroviral therapy," Clinical Infectious Diseases, vol. 40, no. 6, pp. 868-873, 2005.

[23] J. O. A. Abalaka, "Attempts to cure and prevent HIV/AIDS in central Nigeria between 1997 and 2002: opening a way to a vaccine-based solution to the problem?" Vaccine, vol. 22, no. 29-30, pp. 3819-3828, 2004.

[24] V. A. Ngu and F. Ambe, "Effective vaccines against and immunotherapy of the HIV: a preliminary report (1)," Journal of the Cameroon Academy of Sciences, vol. 1, pp. 2-8, 2001.

[25] V. Jirathitikal and A. S. Bourinbaiar, "Preclinical and safety studies of V-1 Immunitor," International Journal of Biotechnology, vol. 9, no. 3-4, pp. 318-331, 2007.

[26] V. Jirathitikal, O. Metadilogkul, and A. S. Bourinbaiar, "Increased body weight and improved quality of life in AIDS patients following V-1 Immunitor admimnistration," European Journal of Clinical Nutrition, vol. 58, no. 1, pp. 110-115, 2004.

[27] V. Jirathitikal and A. S. Bourinbaiar, "Effect of an oral therapeutic HIV-1 vaccine on aids patients with CD4 count above 250 cells/mm 3 ," Acta Virologica, vol. 48, no. 2, pp. 73-78, 2004.

[28] V. Jirathitikal, P. Sooksathan, O. Metadilogkul, and A. S. Bourinbaiar, "V-1 Immunitor: oral therapeutic AIDS vaccine with prophylactic potential," Vaccine, vol. 21, no. 7-8, pp. 624-628, 2003.

[29] A. S. Bourinbaiar, V. Jirathitikal, O. Metadilogkul, et al., "Phase II placebo-controlled study of V-1 Immunitor as a therapeutic modality for treatment of HIV," Journal of Clinical Virology, vol. 31, supplement 1, pp. S55-S62, 2004.

[30] O. Metadilogkul, V. Jirathitikal, and A. S. Bourinbaiar, "Prolonged survival of end-stage AIDS patients immunized with therapeutic HIV vaccine V-1 Immunitor," Biomedicine \& Pharmacotherapy, vol. 59, no. 8, pp. 469-473, 2005.

[31] A. S. Bourinbaiar and K. Ajuang-Simbiri, "Simple procedure for estimating the efficiency of PCR," Molecular Biotechnology, vol. 6, no. 1, pp. 87-89, 1996.

[32] M. J. Roy, J. J. Damato, and D. S. Burke, "Absence of true seroreversion of HIV-1 antibody in seroreactive individuals," Journal of the American Medical Association, vol. 269, no. 22, pp. 2876-2879, 1993.

[33] O. Metadilogkul, S. Sribantao, and S. Buraparat, Investigational Report on HIV-Positive Patients Who Became HIVNegative (Report in Thai), Office of Occupational and Environmental Medicine, Ministry of Public Health and Occupational and Environmental Medicine Association of Thailand, Rajavithi General Hospital, Bangkok, Thailand, 2002.

[34] L. M. Cummins, K. J. Weinhold, T. J. Matthews, et al., "Preparation and characterization of an intravenous solution of IgG from human immunodeficiency virus-seropositive donors," Blood, vol. 77, no. 5, pp. 1111-1117, 1991.

[35] F. A. Koning, T. J. K. van der Vorst, and H. Schuitemaker, "Low levels of human immunodeficiency virus type 1 DNA in high-risk seronegative men," Journal of Virology, vol. 79, no. 10, pp. 6551-6553, 2005.

[36] D. Zagury, R. Léonard, M. Fouchard, et al., "Immunization against AIDS in humans," Nature, vol. 326, no. 6110, pp. 249-250, 1987.
[37] A. S. Bourinbaiar, R. S. Root-Bernstein, R. Abulafia-Lapid, et al., "Therapeutic AIDS vaccines," Current Pharmaceutical Design, vol. 12, no. 16, pp. 2017-2030, 2006.

[38] E. J. Stott, "Anti-cell antibody in macaques," Nature, vol. 353, no. 6343 , p. 393,1991

[39] L. O. Arthur, J. W. Bess Jr., R. C. Sowder II, et al., "Cellular proteins bound to immunodeficiency viruses: implications for pathogenesis and vaccines," Science, vol. 258, no. 5090, pp. 1935-1938, 1992.

[40] L. Lopalco, C. Pastori, A. Cosma, et al., "Anti-cell antibodies in exposed seronegative individuals with HIV type 1neutralizing activity," AIDS Research and Human Retroviruses, vol. 16, no. 2, pp. 109-115, 2000.

[41] M. Spruth, H. Stoiber, L. Kacani, D. Schönitzer, and M. P. Dierich, "Neutralization of HIV type 1 by alloimmune sera derived from polytransfused patients," AIDS Research and Human Retroviruses, vol. 15, no. 6, pp. 533-543, 1999.

[42] G. M. Shearer, L. A. Pinto, and M. Clerici, "Alloimmunization for immune-based therapy and vaccine design against HIV/ AIDS," Immunology Today, vol. 20, no. 2, pp. 66-71, 1999.

[43] A. S. Bourinbaiar and R. Abulafia-Lapid, "Autoimmunity, alloimmunization and immunotherapy of AIDS," Autoimmunity Reviews, vol. 4, no. 6, pp. 403-409, 2005.

[44] R. Abulafia-Lapid, S. Mayan, Z. Bentwich, et al., "T-cell vaccination against anti-CD4 autoimmunity in HIV-1 subtypes B and C-infected patients-an extended open trial," Vaccine, vol. 23, no. 17-18, pp. 2149-2153, 2005.

[45] M. Page, A. Ojugo, N. Imami, G. Hardy, F. Gotch, and N. Almond, "Specificity of anti-human leukocyte antigen antibody responses after immunization with Remune, an inactivated HIV-1 vaccine," AIDS, vol. 21, no. 3, pp. 375-377, 2007.

[46] E. Israeli, R. Safadi, A. Melhem, et al., "Induction of oral immune regulation towards liver-extracted proteins for treatment of chronic HBV and HCV hepatitis: results of a phase I clinical trial," Liver International, vol. 24, no. 4, pp. 295-307, 2004.

[47] D. Batdelger, D. Dandii, V. Jirathitikal, and A. S. Bourinbaiar, "Open label trial of therapeutic hepatitis $\mathrm{B}$ vaccine $\mathrm{V}-5$ Immunitor (V5) delivered by oral route," Letters in Drug Design and Discovery, vol. 4, no. 8, pp. 540-544, 2007.

[48] D. Batdelger, D. Dandii, V. Jirathitikal, and A. S. Bourinbaiar, "Open-label trial of therapeutic immunization with oral V-5 Immunitor (V5) vaccine in patients with chronic hepatitis C," Vaccine, vol. 26, no. 22, pp. 2733-2737, 2008.

[49] B. Autran, R. L. Murphy, D. Costagliola, et al., "Greater viral rebound and reduced time to resume antiretroviral therapy after therapeutic immunization with the ALVAC-HIV vaccine (vCP1452)," AIDS, vol. 22, no. 11, pp. 1313-1322, 2008.

[50] M. Cornelissen, S. Jurriaans, J. M. Prins, M. Bakker, and A. C. van der Kuyl, "Absence of seroreversion in 80 HAARTtreated HIV-1 seropositive patients with at least five-years undetectable plasma HIV-1 viral load," AIDS Research and Therapy, vol. 3, no. 1, p. 3, 2006.

[51] C. B. Hare, B. L. Pappalardo, M. P. Busch, et al., "Seroreversion in subjects receiving antiretroviral therapy during acute/early HIV infection," Clinical Infectious Diseases, vol. 42, no. 5, pp. 700-708, 2006.

[52] J. W. Tang, B. C. K. Wong, E. Lam, et al., "Failure to confirm HIV infection in two end-stage HIV/AIDS patients using a popular commercial line immunoassay," Journal of Medical Virology, vol. 80, no. 9, pp. 1515-1522, 2008.

[53] SUICIDE, Ministry to Probe Death of Medical Technician, The Nation, Bangkok, Thailand, 2002. 


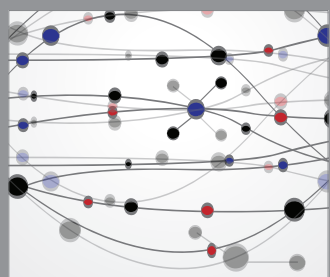

The Scientific World Journal
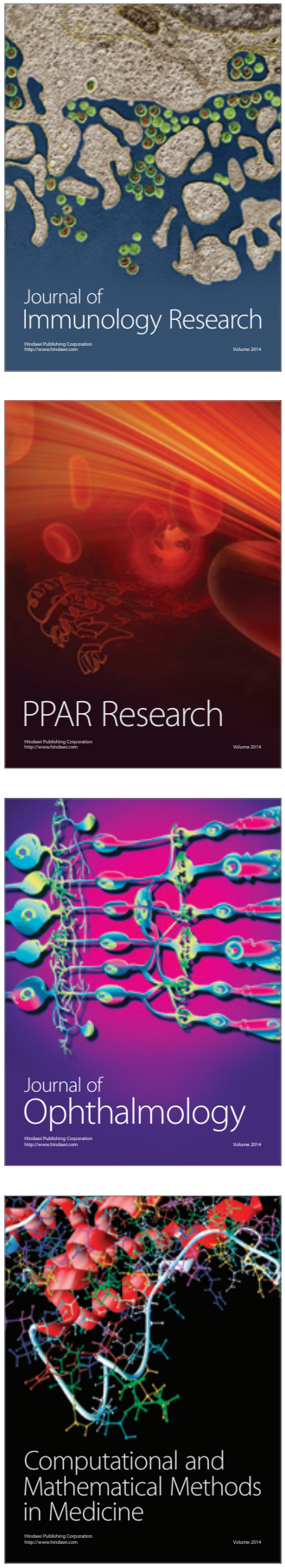

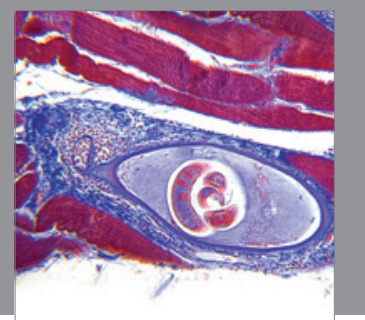

Gastroenterology

Research and Practice
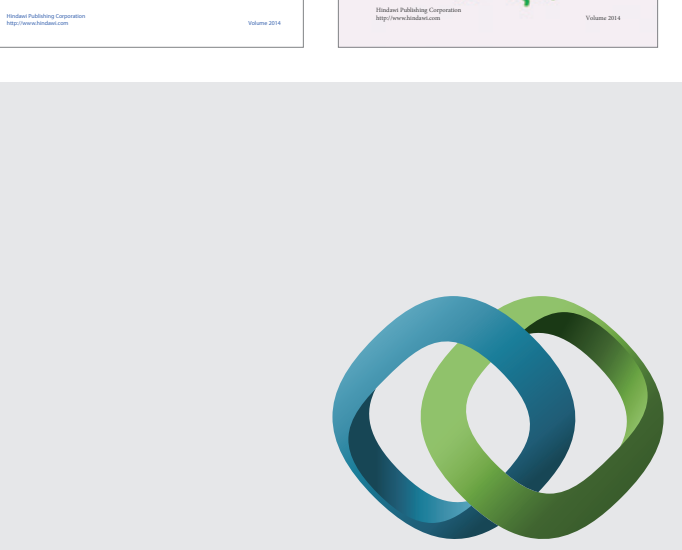

\section{Hindawi}

Submit your manuscripts at

http://www.hindawi.com
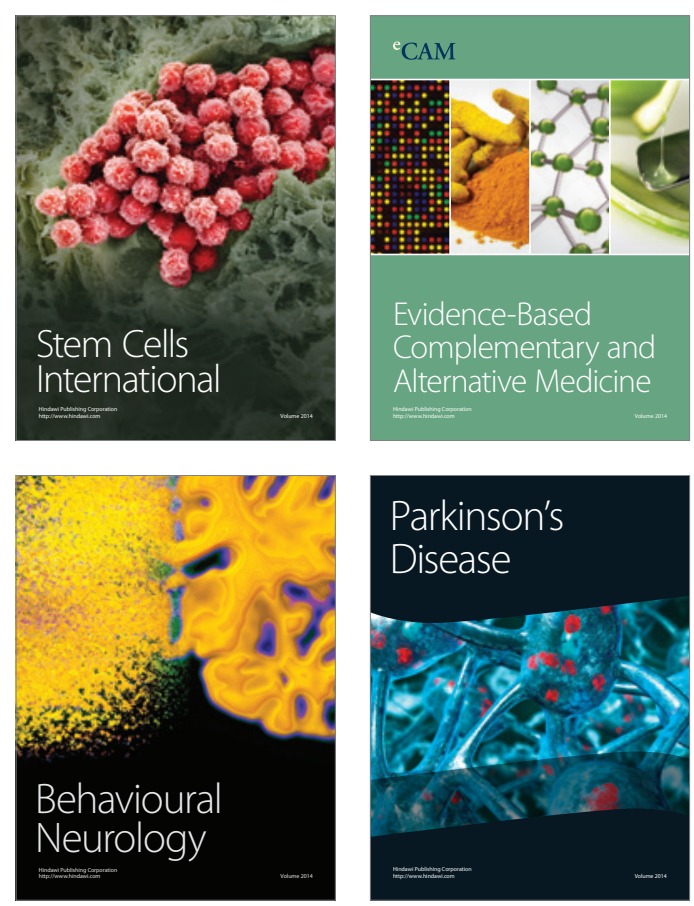

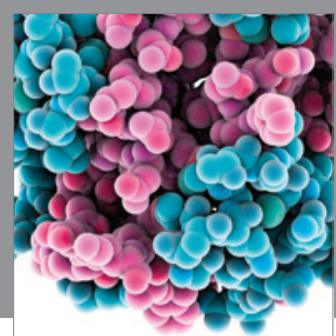

Journal of
Diabetes Research

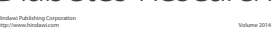

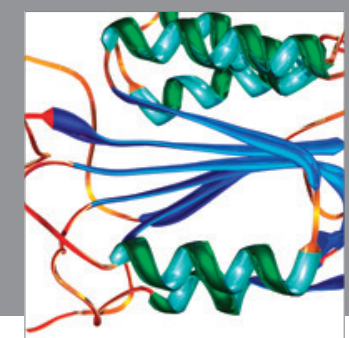

Disease Markers
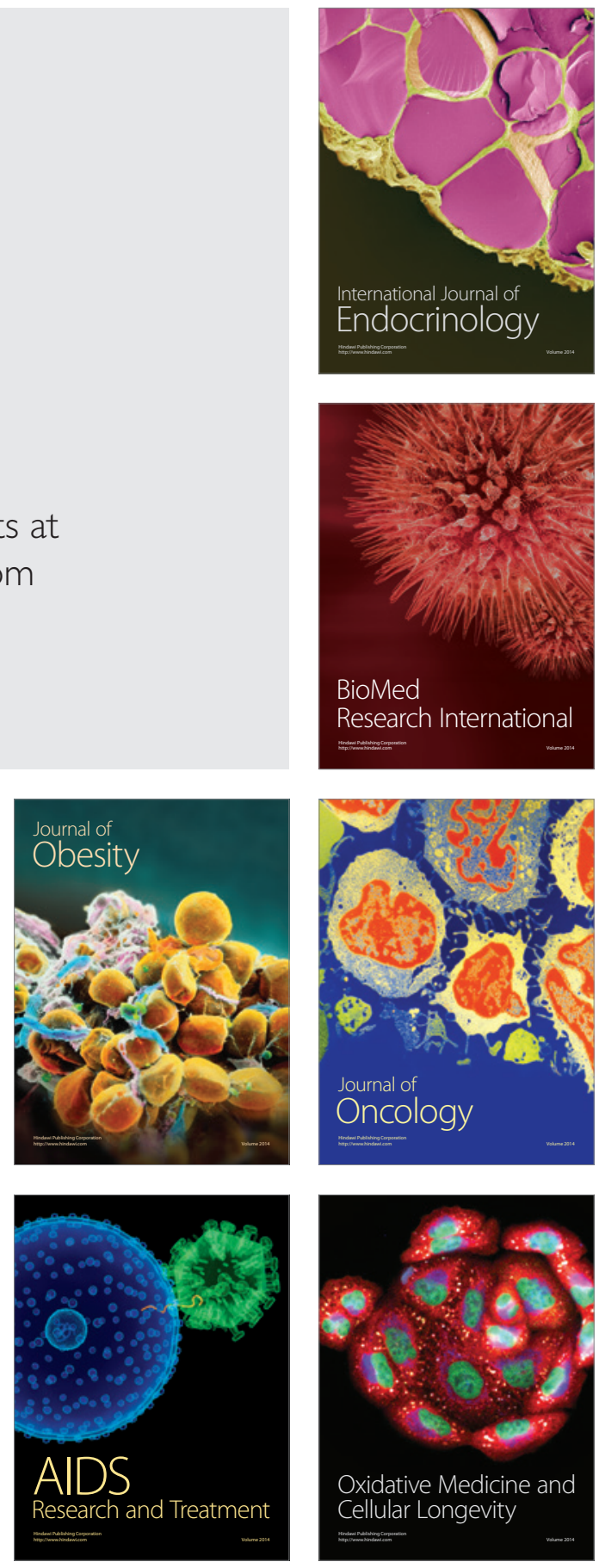